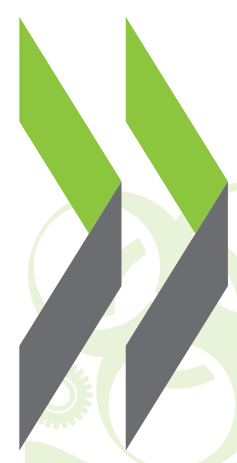

How much will the literacy level of the working-age population change from now to 2022?

Adult Skills

in Focus \#7

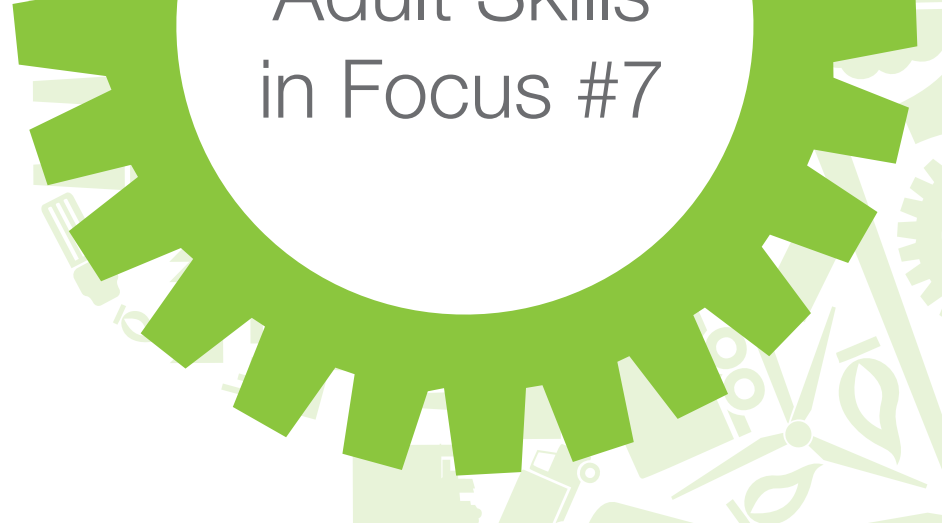




\section{ADULT SKILLS}

\section{INFOCUS}

- By 2022, the average proficiency in literacy of the 16-65 year-old population should have increased slightly in most of the countries that took part in the first cycle of the Programme for the International Assessment of Adult Competencies (PIAAC).

- This positive trend will be fuelled by the arrival of young, better-educated cohorts and the simultaneous exit of the oldest cohorts, whose skills are generally weaker.

The Survey of Adult Skills (PIAAC) measures the skills of working-age adults (16-65 yearolds) in literacy, numeracy and digital problem solving. The first assessment took place between 2011 and $2014^{1}$ and a second one will follow up a decade later. What changes may have taken place by that time, if current demographic trends and institutional environments remain unchanged? Should we expect the literacy proficiency of the adult population to have declined between 2012 and 2022 or to have improved? And by how much? Whatever the answer, it will have huge implications for the well-being of societies. The results of the first cycle underlined the many advantages of enjoying a good level of proficiency. People with greater literacy proficiency are more likely to report being in good health or to take part in civic activities, are more trusting of others, better paid and less likely to be unemployed. In addition, the trend followed by each country's literacy proficiency also influences its level of productivity and hence its future economic potential.

\section{This change is driven by demographics and the impact of ageing on literacy}

Two forces will drive the change in literacy proficiency of the adult population between 2012 and 2022.

The first is one we can no longer influence: it relates to demographic changes. Most people who were aged between 16 and 65 in 2012 will still be aged between 16 and 65 ten years later. From one year to the next, this population changes only at its margins. Each cohort will shrink as some members die, especially among those already aged over 50. Cohorts that were previously too young will reach 16 and, conversely, the oldest cohorts will reach 65 . All cohorts except the future young cohorts are already present in the first PIAAC cycle.
The second is one we can act on today, it relates to the development of individuals' skills over time (age effects). While the population aged between 16 and 65 will remain largely unchanged from one year to the next, the skills of each individual in that population will not remain static. Age plays a decisive role in people's skills, with changes during their lifetimes depending on the intensity of their learning activities, their ongoing and regular use of those skills, and biological ageing. Which of these influences prevails is essentially determined by age and particularly by whether individuals have completed their years of education. 
The youngest will continue to mature and many will pursue their studies and see their skills increase. Among the older cohorts, individuals might maintain their skills, acquire new ones or lose others, according to factors such as their professional circumstances.

\section{Literacy proficiency should increase in all countries}

The modelling shows that these two forces combined should lead to a modest but general improvement in the average literacy proficiency of the 16-65 age group by 2022 Figure 1 presents the projected average literacy scores for each country in 2022, compared to the levels measured in 2012. Over this ten-year period, the increase amounts to between 1 and 10 points, depending on the country, with an average increase of around 5 points. These variations remain small compared to the differences between countries. They are also small in relation to the literacy scale used. In England/Northern Ireland (UK), Greece and New Zealand the literacy level of 16-65 yearolds should remain virtually unchanged. Conversely, Finland, France and Singapore will see more significant improvement, at around 10 points. These projections do not predict any catching-up: the gaps between countries will remain largely stable, and some countries which already had a high level of proficiency in 2012 can also expect significant improvements.

Figure 1 / Literacy scores for the first PIAAC cycle and projections for 2022

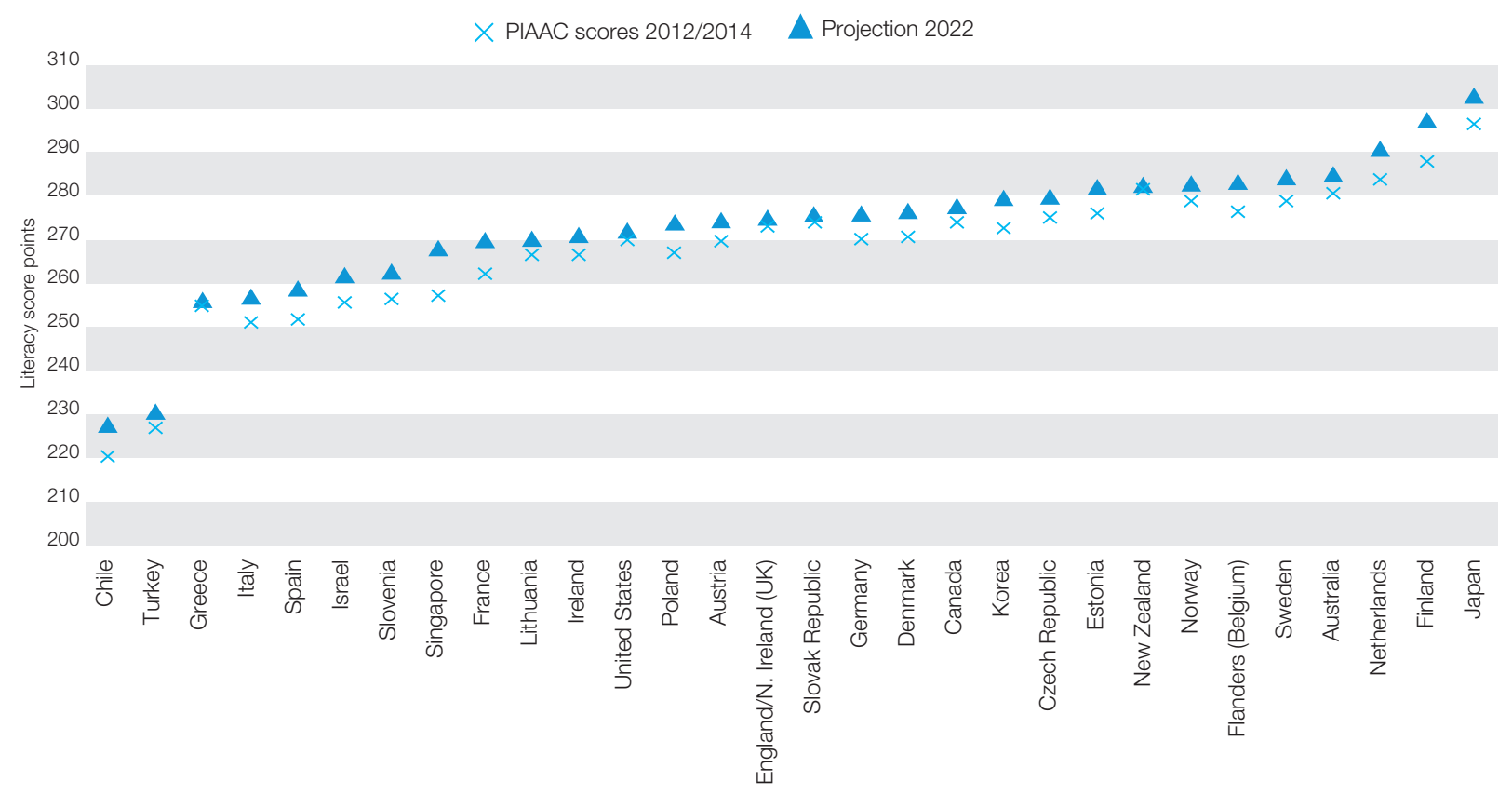

Source: Survey of Adult Skills (PIAAC) $(2012,2015)$. 


\section{ADULT SKILLS}

\section{INFOCUS}

\section{This trend is mainly driven by demographic change}

The regularity of the projected changes and their positive direction in all countries may seem surprising, but can be traced back to the demographic component. Figure 2 compares the projections to the change which would occur if demographics alone were taken into account. In all countries, the change due to the demographic component is positive and is only marginally modified, generally in a negative direction, by age effects. The change is closely associated with the entry of younger cohorts, who will have reached the ages of 16-25 in 2022, and the exit of the oldest cohorts, who were aged 55-65 in 2012 and who will be over 65 in 2022. The size of the increase is clearly linked to the differences in literacy proficiency as measured by PIAAC between a country's 16-24 year-olds and its 55-65 year-olds. In countries where the literacy proficiency of 55-65 year-olds is much lower than for 16-24 year-olds (Finland, France and Singapore), there is a strong projected improvement, whereas it is considerably lower in countries where there is less difference in proficiency levels (England/ Northern Ireland (UK), Slovak Republic and the United States). In contrast, migrant flows will have only a minor impact, even in countries where a large influx is expected (Australia, Canada and Norway).

\section{Figure 2 / Projected changes between 2012 and 2022, with or without age effects}

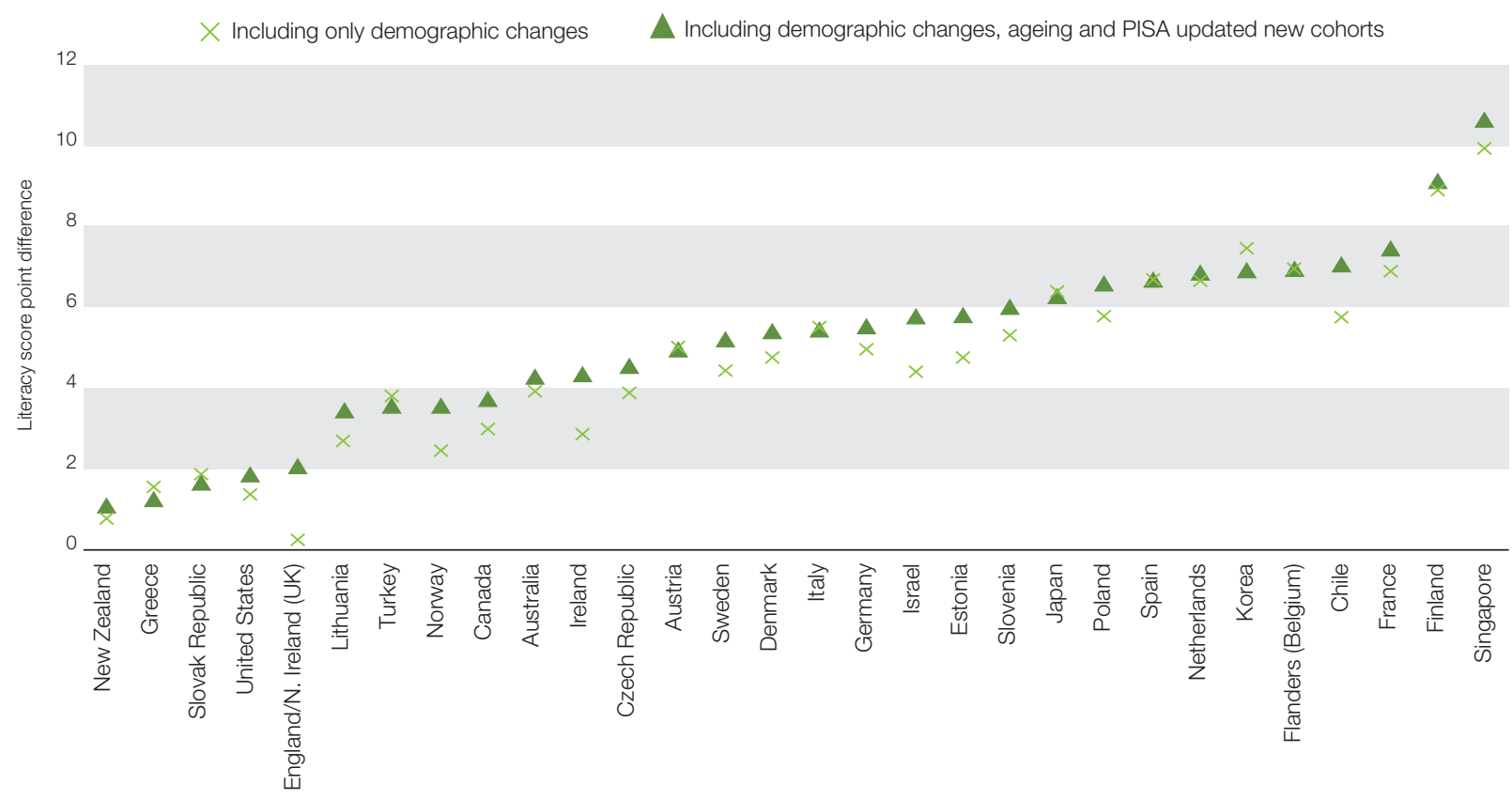

Source: Survey of Adult Skills (PIAAC) $(2012,2015)$.

These projections, rather than being predictions, signal trends and orders of magnitude. In particular, as is explained in the methodology box below, it is very difficult to model age effects on literacy. This has been simplified in this instance by assuming that the changes between 2012 and 2022 will be similar to those observed between 2003 (or 2007) and 2012. The projections do not take account of many phenomena related 
to age effects, even though many of them are the focus of public policies. Each country will make changes to its education system, employment policies, vocational training and retirement age which are likely to affect its skills distribution in 2022. The projections here cannot show the consequences of these policies, which have been or are going to be implemented, but they will be visible in the data collected in the second cycle of PIAAC.

\section{Methodology}

The projections are based on simple assumptions as to demographic changes and the evolution of proficiency with age.

First, the population structure in 2022 is based on World Bank projections. It is gender and age-group specific. The projections are reliable over a 10-year horizon provided that no new, significant migration occurs.

Second, as the cohorts aged 16-25 in 2022 were too young to be represented in the first cycle in 2012, they had to be simulated. This was done by duplicating the cohorts of the same age in 2012 and modifying their performance in proportion with the changes observed in the Programme for International Student Assessment (PISA) for each country.

Finally, the most difficult aspect to model was the impact of the next ten years on the skills of the cohorts included in both 2012 and 2022. Two different methods were used to better assess the robustness of the projections. Both methods were used by the countries involved in both PIAAC and an earlier, similar survey, Adult Literacy and Lifeskills (ALL). The effect of ageing on literacy in the countries which took part in both surveys can be seen by comparing the same cohorts at two different ages, i.e. at the time data were collected for the ALL survey (2003 and 2007), and then for the PIAAC in 2012. An initial model, which is the basis for Figure 1, applies for each age in 2012, and equally in each country, changes identical to those observed on average between the two surveys in the common PIAAC and ALL countries. Given the heterogeneous nature of this group of countries, a second, similar, model was also used, using only data from the United States. In both models, literacy increases with age until the age of 30 , and then starts to fall. In the first model, these two effects largely offset each other, resulting in only a slight downturn for the population as a whole. In the second model, the decline in literacy among the over 30s dominates, and magnifies the downturn observed in the first model, without undermining the general nature of the increase.

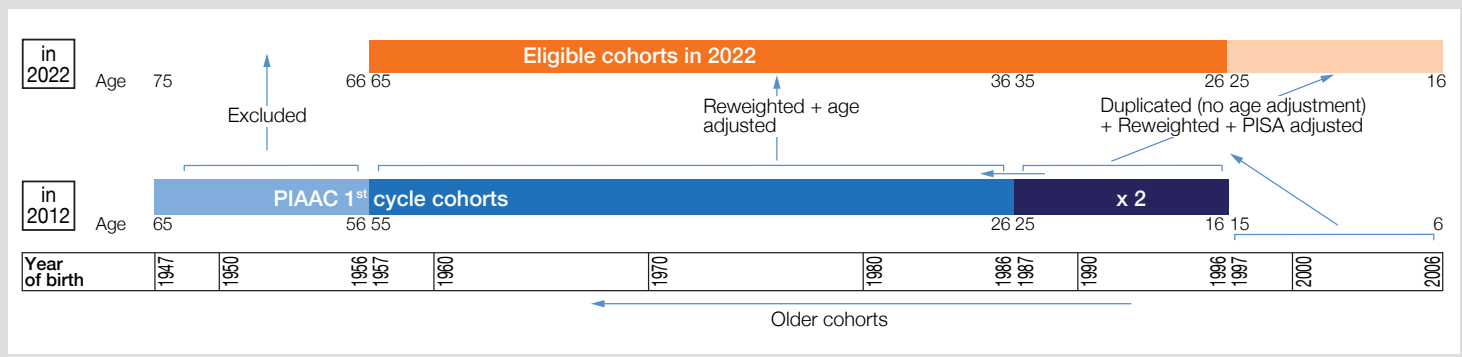




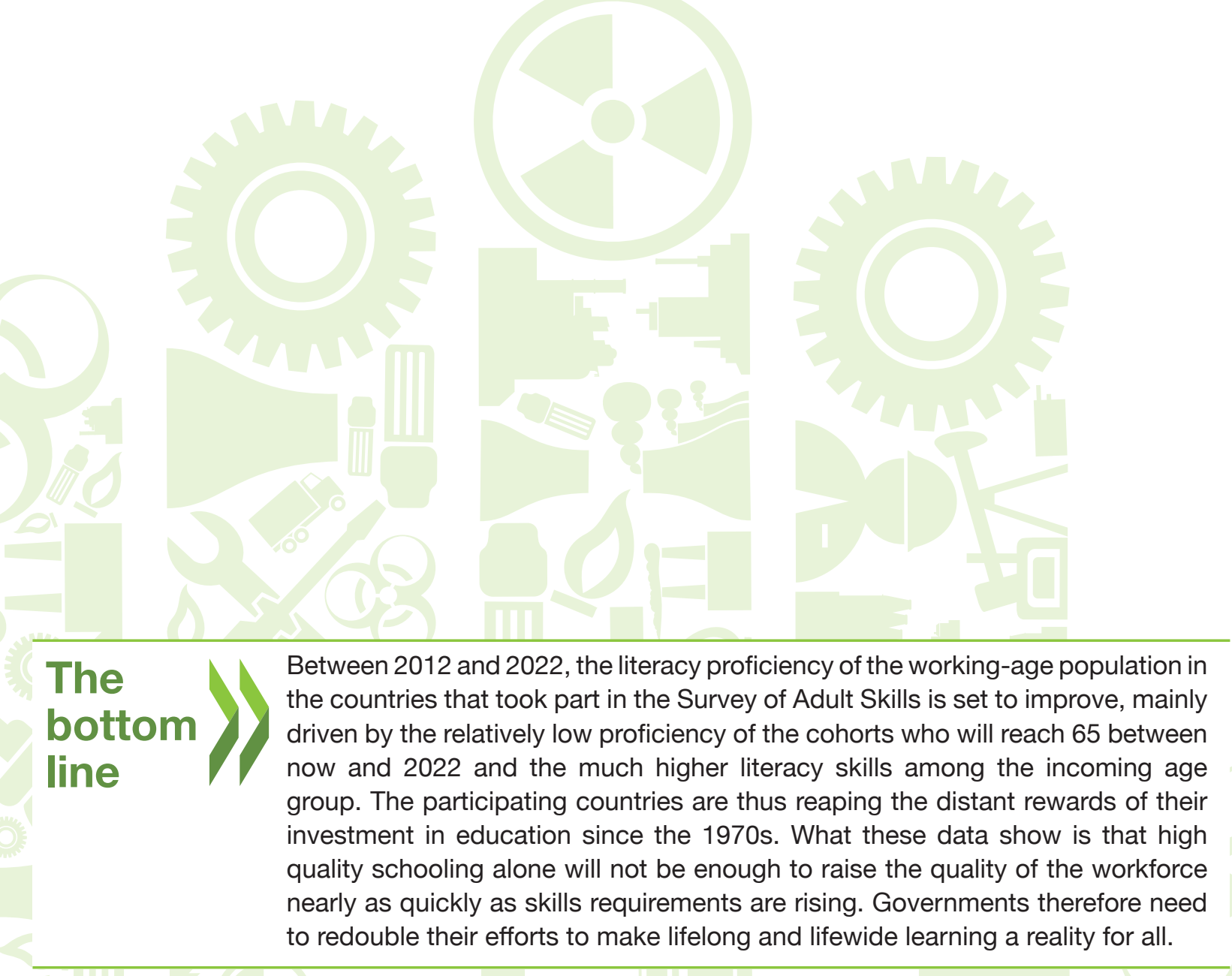

1. Data collection took place in two rounds. Data for countries in the first round was collected in $2011 / 2012$. A smaller set of countries belong to the second round which was collected in 2014/2015. For the sake of clarity, the remainder of the text will only mention 2012. Projections for both rounds target 2022.

\section{> CONTACT: $\quad$ François Keslair (françois.keslair@oecd.org), edu.piaac@oecd.org.}

$>$ VISIT: www.oecd.org/skills/piaac

Education Indicators in Focus - PISA in Focus - Teaching in Focus

The Survey of Adult Skills is a product of the OECD Programme for the International Assessment of Adult Competencies (PIAAC).

This paper is published under the responsibility of the Secretary-General of the OECD. The opinions expressed and the arguments employed herein do not necessarily reflect the official views of OECD member countries.

This document, as well as any data and any map included herein, are without prejudice to the status of or sovereignty over any territory, to the delimitation of international frontiers and boundaries and to the name of any territory, city or area.

You can copy, download or print OECD content for your own use, and you can include excerpts from OECD publications, databases and multimedia products in your own documents, presentations, blogs, websites and teaching materials, provided that suitable acknowledgment of OECD as source and copyright owner is given. All requests for commercial use and translation rights should be submitted to rights@oecd.org.

The statistical data for Israel are supplied by and under the responsibility of the relevant Israeli authorities. The use of such data by the OECD is without prejudice to the status of the Golan Heights, East Jerusalem and Israeli settlements in the West Bank under the terms of international law. 